\title{
Impact of $0.1 \%$ octenidine mouthwash on plaque re-growth in healthy adults: a multi-center phase 3 randomized clinical trial
}

\author{
Yvonne Jockel-Schneider ${ }^{1}$. Ulrich Schlagenhauf ${ }^{1} \cdot$ Hari Petsos $^{2} \cdot$ Stefan Rüttermann $^{3}$ - Jana Schmidt ${ }^{4} \cdot$ Dirk Ziebolz $^{4}$. \\ Christian Wehner ${ }^{5} \cdot$ Markus Laky $^{5} \cdot$ Thea Rott $^{6} \cdot$ Michael Noack $^{6} \cdot$ Barbara Noack $^{7} \cdot$ Katrin Lorenz $^{7}$ (D)
}

Received: 27 August 2020 / Accepted: 6 January 2021 / Published online: 22 January 2021

(C) The Author(s) 2021

\begin{abstract}
Objectives To investigate plaque inhibition of $0.1 \%$ octenidine mouthwash (OCT) vs. placebo over 5 days in the absence of mechanical plaque control.

Materials and methods For this randomized, placebo-controlled, double-blind, parallel group, multi-center phase 3 study, 201 healthy adults were recruited. After baseline recording of plaque index (PI) and gingival index (GI), collection of salivary samples, and dental prophylaxis, subjects were randomly assigned to OCT or placebo mouthwash in a 3:1 ratio. Rinsing was performed twice daily for $30 \mathrm{~s}$. Colony forming units in saliva were determined before and after the first rinse. At day 5, PI, GI, and tooth discoloration index (DI) were assessed. Non-parametric van Elteren tests were applied with a significance level of $p<0.05$.

Results Treatment with OCT inhibited plaque formation more than treatment with placebo (PI: 0.36 vs. $1.29 ; p<0.0001$ ). OCT reduced GI ( 0.04 vs. placebo $0.00 ; p=0.003)$ and salivary bacterial counts $(2.73$ vs. placebo $0.24 \mathrm{lgCFU} / \mathrm{ml} ; p<0.0001)$. Tooth discoloration was slightly higher under OCT (DI: 0.25 vs. placebo $0.00 ; p=0.0011$ ). Mild tongue staining and dysgeusia occurred.

Conclusions OCT $0.1 \%$ mouthwash inhibits plaque formation over 5 days. It therefore can be recommended when regular oral hygiene is temporarily compromised.

Clinical relevance When individual plaque control is compromised, rinsing with octenidine mouthwash is recommended to maintain healthy oral conditions while side effects are limited.
\end{abstract}

Keywords Octenidine $\cdot$ Mouthrinse $\cdot$ Bacterial counts $\cdot$ Plaque index $\cdot$ Gingival index $\cdot$ Discoloration index

Katrin Lorenz

katrin.lorenz@tu-dresden.de

1 Department of Periodontology, University Hospital Wuerzburg, Pleicherwall 2, 97070 Wuerzburg, Germany

2 Department of Periodontology, Johann Wolfgang Goethe-Universität Frankfurt am Main, Theodor-Stern-Kai 7, 60596 Frankfurt am Main, Germany

3 Department of Conservative Dentistry, Johann Wolfgang Goethe-Universität Frankfurt am Main, Theodor-Stern-Kai 7, 60596 Frankfurt am Main, Germany

4 Department of Cariology, Endodontology and Periodontology, University of Leipzig, Liebigstraße 12, 04103 Leipzig, Germany

5 Division of Conservative Dentistry and Periodontology, Medical University of Vienna, Sensengasse 2a, 1090 Wien, Austria

6 Department of Operative Dentistry and Periodontology, University of Cologne, Kerpener Str. 32, 50931 Köln, Germany

7 Department of Periodontology, Technische Universität Dresden, Fetscherstr. 74, 01307 Dresden, Germany

\section{Introduction}

Antiseptic mouthwashes are commonly used in oral home care. They are recommended particularly in situations where the performance of efficacious mechanical plaque control is temporarily or permanently impaired, like in individuals in need of care, after oral surgical interventions, during orthodontic therapy with fixed appliances or as adjunct for gingivitis or periodontitis therapy [1-4]. Next to a mandatory very low systemic cytotoxicity, antiseptic agents suitable for use in a mouthwash need to have a long-lasting substantivity. This prevents an agent to be washed out of the mouth immediately by the salivary flow. In addition, a broad, unspecific antibacterial efficacy towards all bacterial species colonizing the oropharynx is essential [5-8].

Presently, chlorhexidine (CHX), a bisbiguanide antiseptic, comprehensively meeting all those requirements, is the most 
widely used antimicrobial agent in mouthwashes. Its clinical efficacy has been verified by a multitude of studies $[9,10]$.

More recently, octenidine dihydrochloride, a bispyridinamine, came into the focus of interest as another particularly suitable agent to be used in oral antiseptics due to properties rivaling those of CHX $[11,12]$. It has an even lower systemic toxicity than CHX [13-15] possibly attributable to the lack of an amide and ester structure in its molecule [16]. Octenidine shows excellent and long-lasting adhesion to mucosal surfaces via its negative charge [17] and physically interacts with bacterial cell membrane components [18]. Its ability to attach to cells results in a residual depot effect on skin or wound tissue $[19,20]$. Octenidine develops a broad antimicrobial activity, affecting Gram-positive and Gramnegative bacteria, chlamydiae, mycoplasmata, and fungi $[12$, $21,22]$. In clinical trials, octenidine showed promising results as a mouthwash agent regarding the reduction of bacteria and plaque inhibition [23].

\section{Aim}

It was the aim of this clinical trial to evaluate the inhibitory effect of a $0.1 \%$ OCT mouthwash on plaque re-growth over 5 days in the absence of mechanical plaque control in healthy adult subjects, using a modified plaque re-growth model [24].

\section{Null hypothesis}

No significant difference between both experimental groups regarding plaque re-growth assessed by plaque index (PI) [25] 5 days after initial professional mechanical plaque removal (PMPR) and the twice daily repeated application of the OCT mouthwash in comparison to the placebo mouthwash in the complete absence of personal mechanical plaque control.

\section{Material and methods}

\section{Trial design}

The investigation was designed as a prospective, randomized, placebo-controlled, double-blind, parallel group, multi-center phase 3 study, divided into two studies OML-III-A and OMLIII-B. OML-III-A took place at the study centers of Dresden, Frankfurt, and Leipzig from January to December 2018. OML-III-B was performed at the study centers in Wuerzburg, Cologne, and Vienna from January to September 2018. The study was conducted in accordance with the principles of Good Clinical Practice (GCP) and the Declaration of Helsinki. It was approved by the ethics committees of the participating centers (study A: ethics committee of the University of Dresden EK 342082017, study B: ethics committee of the University of Wuerzburg 203/17_ff-me) and was registered at clinicaltrials.gov (study A: NCT03322124; study B NCT03378401) and the European Clinical Trials Database (study A: EudraCT No.: 2017-001697-42, study B: EudraCT No.: 2017-001698-18). All participants were informed about the study and signed the informed consent declaration. The studies were registered at clinicaltrials.gov: NCT03322124, NCT03378401.

The results presented in the following are based on the joint data set of the OML-III-A and OML-III-B studies, which followed identical study protocols and were performed concomitantly.

\section{Study population}

Participants (male and female) were recruited among systemically healthy dental patients visiting the study centers in Dresden, Frankfurt, Cologne, Vienna, and Wuerzburg or among healthy volunteers from the resident population being asked for study participation by local advertisement.

Inclusion criteria were as follows: age $\geq 18$ years; total mean gingival index GI $\leq 1.5$ [26]; a minimum of 20 sound teeth including the Ramfjord teeth $(16,21,24,36,41,44)$ or their replacements $(17,11,25,37,31,45)[27,28]$; and 10 natural anterior teeth, necessary for the assessment of the discoloration index (excluding teeth restored with crowns or large vestibular fillings while teeth with only minor interdentally or orally located fillings were included).

Exclusion criteria were as follows: severe systemic diseases; necessity of antibiotic endocarditis prophylaxis; untreated caries with cavitation; presence of a GI score 3 at any tooth [26]; manifestation of periodontitis exceeding the presence of a Periodontal Screening and Recording Index (PSR) score 2 in more than two sextants or a PSR score $>3$ in any sextant [29]; manifestation of other oral diseases including gingival overgrowth or mucosal diseases; orthodontic therapy; restoration with removable dentures; antibiotic therapy < 3 months prior to baseline examination; intake of systemically or locally acting corticosteroids (e.g., asthma sprays); xerostomia; hypersensitivity or allergy to the test product and its ingredients or to medications displaying a similar chemical structure; participation in another clinical study within the last 4 weeks before enrolment in and during this study; and pregnancy or breastfeeding.

\section{Composition and application of the experimental mouthwashes}

The experimental mouthwashes were manufactured by NextPharma GmbH (Göttingen, Germany). They contained glycerol, sodium gluconate, citric acid, disodium phosphate dihydrate, macrogolglycerol hydroxystearate $40 \mathrm{EO}$, mint cool flavor PHL-167319, sucralose, and $0.1 \%$ octenidine 
(OCT mouthwash only) or phenoxyethanol $0.5 \%$ (placebo mouthwash only).

Study participants were instructed to rinse their mouth with $10 \mathrm{ml}$ of the assigned mouthwash twice daily for $30 \mathrm{~s}$ each over a period of 5 days, resulting in a total of 10 applications. For dosing, a measuring cup was provided with the study drug package.

\section{Study outcomes}

Primary study outcome Primary study outcome was the amount of plaque re-growth assessed by plaque index (PI) [25] 5 days after initial PMPR and the twice daily repeated application of the OCT mouthwash in comparison to the placebo mouthwash in the complete absence of personal mechanical plaque control. Following a modified plaque re-growth model (Addy et al., [24]), PI was recorded at screening (Vsc), baseline (V1), and at the final study visit (V2) on the Ramfjord teeth or their replacements at four sites per tooth (distovestibular, vestibular, mesiovestibular, and oral). The null hypothesis to be tested was that no significant difference regarding mean plaque index score existed between both experimental groups at V2.

Secondary study outcomes Secondary study outcomes were the reduction of salivary bacterial counts after a single application of the experimental mouthwashes for $30 \mathrm{~s}$ at baseline and changes in mean GI scores [26] and DI scores [30] from baseline to the end of the study between OCT and placebo groups.

Assessment of salivary bacterial counts For the assessment of salivary bacterial counts, the study participants were asked to rinse their mouth with $5 \mathrm{ml}$ of sterile water for $30 \mathrm{~s}$ and to spit the originating saliva-water volume into a sterile screw-cap test tube. The samples were subsequently serially diluted, inoculated on Columbia blood agar plates $+5 \%$ sheep blood (bioMérieux SA, Marcy l'Etoile, France) and incubated at $37^{\circ} \mathrm{C}$ for $48 \mathrm{~h}$. The number of detected colony forming units (CFU) was used to calculate the number of $\mathrm{CFU} / \mathrm{ml}$ for the respective dilution.

Assessment of gingival health Gingival health was assessed by recording the gingival index [26] at Vsc, V1, and V2 on the Ramfjord teeth or their replacements at four sites per tooth (distovestibular, vestibular, oral, and mesiovestibular).

Tooth discoloration and questionnaire The presence and extent of tooth discoloration were assessed at V1 after PMPR and after 5 days of rinsing (V2) at the vestibular sites of the anterior teeth according to the criteria of the discoloration index [30].
Furthermore, the study participants were instructed to document their daily consumption of staining beverages like coffee, tea, red wine, and juices, the use of chewing gum and menthol-containing lozenges, as well as tobacco smoking by a self-reported questionnaire.

Safety At baseline and at the end of the study (day 5), the study participants were interviewed for the occurrence of related or unrelated adverse events.

Verification of application compliance Application compliance was verified by instructing the study participants to return all empty, partially used, or unused containers of the experimental mouthwashes at the end of the study (V2). The volume of applied mouthwashes was calculated as difference in the weight of the assigned supply of mouthwash containers before handing out and after returning them to the study center.

Calibration, blinding and randomization All clinical examiners of the participating study centers had been trained and calibrated prior to the onset of the study following established guidelines [31].

Investigators and other study personnel were blinded to the assignment of the study participants to the treatment groups throughout the study. Both experimental mouthwashes (OCT/placebo) were provided in bottles with identical packaging and labelling and had an identical appearance, color, and taste to ensure blinding of participants. The handing out to the study subjects in a 3:1 ratio (OCT vs. placebo) was performed by a study nurse not involved in the recording of the study data using a computer-generated randomization list. Randomization was stratified for GI baseline score (mean GI $\leq 1.0$ vs. mean GI > 1.0).

Screening visit (Vsc) At the screening visit, eligibility criteria were checked, and demographics, medical history, concomitant medication, and smoking habits were documented. PI [25] and GI [26] were recorded.

Visit 1 (V1, day 1, baseline) At visit 1, eligibility criteria were re-checked, GI baseline scores were recorded, and a saliva sample was collected (Fig. 1). Subsequently the participants were randomly assigned to the OCT or the placebo group, performed a first supervised rinse with the assigned mouthwash for $30 \mathrm{~s}$, followed $1 \mathrm{~min}$ later by the collection of another saliva sample. Subsequently all teeth were thoroughly cleaned from adhering bacterial biofilms, calculus, or superficial stains by PMPR using ultrasonic scalers and air-polishing devices.

The presence of non-removable tooth stains was documented using the DI, and participants were asked to perform 
Fig. 1 Study flow chart
Treatment Period

\begin{tabular}{|c|c|c|}
\hline Screening visit & \multirow{2}{*}{$\begin{array}{l}\text { Visit } 1 \\
\text { Day } 1\end{array}$} & Visit 2 \\
\hline-14 to -3 days prior to $\mathrm{V} 1$ & & Day 5 \\
\hline Inspection of oral cavity & Inspection of oral cavity & Inspection of oral cavity \\
\hline Plaque index & Gingival index & Plaque index \\
\hline \multirow[t]{4}{*}{ Gingival index } & Saliva samples/Bacterial counts & Gingival index \\
\hline & PMPR & Tooth discoloration index \\
\hline & Tooth discoloration index & Questionnaire eating habits \\
\hline & Questionnaire eating habits & Adverse events \\
\hline
\end{tabular}

a second supervised rinse. Instructions were given to repeat the rinsing twice daily at home for the next 4 days while refraining from any kind of mechanical plaque control and to perform the final rinse in the morning of day 5 within $4 \mathrm{~h}$ before the final examination. Finally, all participants received a supply of the assigned mouthwash sufficient for the next 5 days and a questionnaire for the self-reported documentation of consumed food and beverages during the observation period.

Visit 2 (V2, day 5, final examination) At visit 2, the study participants returned the assigned mouthwash followed by the final assessment of GI, PI, and DI and the collection of completed questionnaires. A final PMPR concluded the study.

\section{Statistical analysis}

Sample size calculation Sample size calculations performed for each study (OML-III-A/OML-III-B) revealed a number of 75 and 25 study subjects (OCT/placebo respectively) to be sufficient to detect a difference in mean PI of -0.9 between the groups with a given power of $p>0.99$, a given level of significance of $p<0.05$, and an assumed mean PI score of $1.5 \pm 0.6$ for the placebo group.

Analysis of the primary outcome Due to lack of normal distribution of data, the primary study outcome mean PI at day 5 of the trial was analyzed using van Elteren test ( 1 -sided, $p<0.025)$. To assess the potential impact of covariables, an additional analysis of co-variance (ANCOVA) with independent variables for treatment group, gingival status at V1 (factor for stratified randomization), total mean PI at screening, and study center was performed.

Analysis of secondary outcomes Statistical analysis of the data of secondary study outcomes was performed by the van Elteren test using a 2-sided significance level of $p<0.05$. The DI data were analyzed with both the van Elteren test and ANCOVA using a 2-sided significance level of $p<0.05$.

\section{Results}

\section{Recruitment, drop-outs, and protocol violations}

Recruitment and drop-outs are depicted in the CONSORT [32] flow diagram in Fig. 2. Two hundred one individuals were recruited and randomly assigned in a ratio of $3: 1$ to the OCT $(n=152)$ or the placebo $(n=49)$ group. Two hundred of them completed the study with a full data set. One participant of the OCT group did not use the assigned mouthwash. Because there were no statistically significant differences between the intention to treat and the per protocol analyses regarding any of the assessed variables, all results depicted in the following are based on the intention to treat analysis.

\section{Demographic data}

The demographic data of the study participants are displayed in Table 1. Both treatment groups were balanced regarding gender (56\% female/44\% male), age (mean age: 26.2 years), and tobacco use. There were no significant differences between the groups regarding medical history and previous or current use of medication.

\section{Plaque re-growth at day 5 (primary study outcome)}

The results of the plaque re-growth analysis are depicted in Table 2. At V2, the observed median PI score of the OCT group (0.36, range 0.00-2.13) was significantly lower $(p<0.0001$, van Elteren test) than the median PI score of the placebo group (1.29, range 0.04-2.01). Among all confounding variables tested, ANCOVA only revealed a center effect $(p<0.0001)$. The null hypothesis of no difference between both experimental groups at V2 therefore had to be rejected. 
Fig. 2 Consort 2010 flow diagram. Recruitment, drop-outs, and protocol violations during the study observation period

\section{O N S O R T}

TRANSPARENT REPORTING of TRIALS

\section{CONSORT 2010 Flow Diagram}

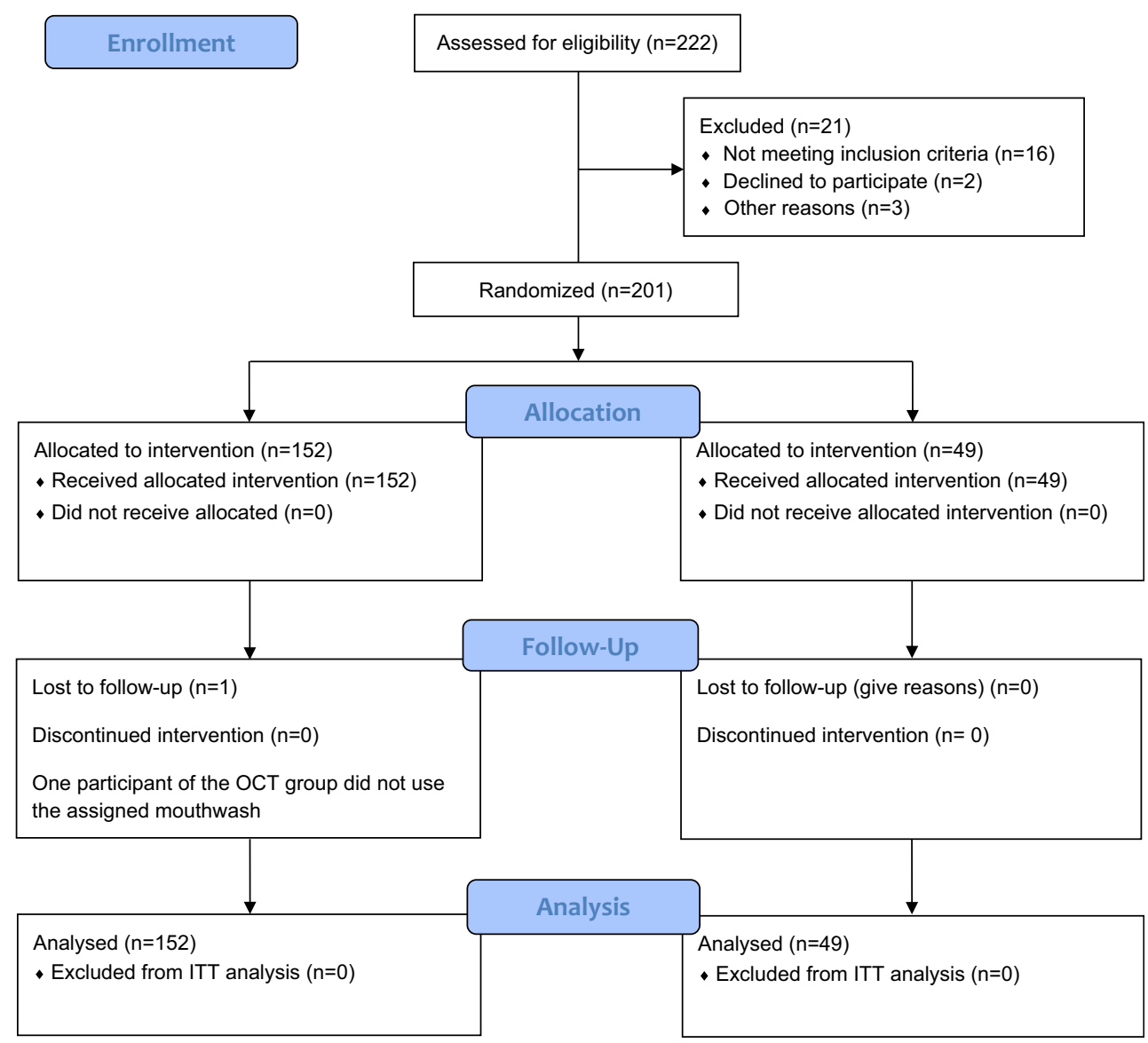

\section{Secondary study outcomes}

\section{Reduction of salivary bacterial counts}

A single rinse with the OCT mouthwash reduced salivary bacterial counts significantly stronger than the placebo mouthwash. The observed median decrease in salivary bacterial counts was $2.73 \mathrm{lgCFU} / \mathrm{ml}$ for the OCT group vs. 0.24
$\operatorname{lgCFU} / \mathrm{ml}$ for the placebo group (2-sided $p<0.0001$; van Elteren test; Table 3).

\section{Gingival index}

The variation of recorded median GI scores within the observation period is displayed in Table 2 . The median reduction of

Table 1 Patient demographics

\begin{tabular}{lccc}
\hline Demographics & $\begin{array}{l}\text { All participants } \\
n=201\end{array}$ & $\begin{array}{l}\text { OCT group } \\
n=152\end{array}$ & $\begin{array}{l}\text { Placebo group } \\
n=49\end{array}$ \\
\hline Age (years) - mean $\pm \mathrm{SD}$ & $26.7 \pm 7.1$ & $26.3 \pm 6.6$ & $25.3 \pm 4.3$ \\
Female gender- $n(\%)$ & $113(56.2 \%)$ & $85(55.9 \%)$ & $28(57.1 \%)$ \\
Non-smokers- $n(\%)$ & $151(75.1 \%)$ & $115(75.7 \%)$ & $36(73.5 \%)$ \\
\hline
\end{tabular}

$S D$ standard deviation, $n$ numbers of subjects, intention to treat analysis set 
Table 2 Plaque index (PI), gingival index (GI), and discoloration index (DI)

\begin{tabular}{|c|c|c|c|c|c|c|c|c|}
\hline & \multicolumn{4}{|c|}{ OCT $(n=152)$} & \multicolumn{4}{|c|}{ Placebo $(n=49)$} \\
\hline & $\mathrm{Vsc}$ & $\mathrm{V} 1$ & $\mathrm{~V} 2$ & Change V1 to V2 & Vsc & $\mathrm{V} 1$ & $\mathrm{~V} 2$ & Change V1 to V2 \\
\hline \multicolumn{9}{|c|}{ PI } \\
\hline Median & 0.33 & 0.00 & 0.36 & $0.36^{*}$ & 0.38 & 0.00 & 1.29 & 1.29 \\
\hline Min-max & $0.00-2.33$ & $0.00-0.00$ & $0.00-2.13$ & $0.00-2.13$ & $0.00-1.83$ & $0.00-0.00$ & $0.04-2.01$ & $0.04-2.01$ \\
\hline \multicolumn{9}{|c|}{ GI } \\
\hline Median & 0.29 & 0.33 & 0.25 & $-0.04^{\#}$ & 0.29 & 0.29 & 0.38 & 0.00 \\
\hline Min-max & $0.00-1.38$ & $0.00-1.46$ & $0.00-1.13$ & -1.04 to 0.75 & $0.00-1.25$ & $0.00-1.04$ & $0.00-1.08$ & -0.54 to 0.58 \\
\hline \multicolumn{9}{|c|}{ DI } \\
\hline Median & - & 0.00 & 0.25 & $0.17^{\dagger}$ & - & 0.00 & 0.00 & 0.00 \\
\hline Min-max & & $0.00-1.00$ & $0.00-2.25$ & -0.16 to 2.25 & & $0.00-0.58$ & $0.00-1.08$ & $0.00-1.08$ \\
\hline
\end{tabular}

*Between OCT and placebo groups; van Elteren test, 2-sided, $p<0.0001$, intention to treat analysis set \#Between OCT and placebo groups; van Elteren test, 2-sided, $p<0.001$, intention to treat analysis set $†$ Between OCT and placebo groups; van Elteren test, 2-sided, $p<0.0011$ intention to treat analysis set

$O C T$ octenidine mouthrinse, $V s c$ screening visit, $V 1$ visit $1, V 2$ visit $2, n$ numbers of subjects, max maximum, min minimum

the recorded mean GI scores between OCT and placebo was statistically significant (2-sided $p<0.001$, van Elteren test).

\section{Discoloration of teeth}

The median change in the DI scores from V1 to V2 was significantly more pronounced in the OCT group when compared to the placebo group (2-sided, $p<0.0011$, van Elteren test, Table 2).

\section{Eating and smoking habits}

A greater proportion of subjects in the OCT than in the placebo group drank tea during the study $(63.3 \%$ vs. $57.0 \%)$, but fewer subjects in this group smoked (25.8\% vs. $32.7 \%$ ) and consumed menthol dragées (13.9\% vs. $20.4 \%)$. Other eating habits were similar between the two groups.

\section{Adverse events}

There were no severe treatment-emergent adverse events (TEAE). Overall, 63 subjects (31.5\%) experienced mild $(n=59)$ or moderate $(n=4)$ TEAEs. In the OCT group, 53 out of 151 participants (35.1\%) reported 71 TEAEs. In the placebo group, 10 out of 49 subjects $(20.4 \%)$ reported the occurrence of 12 TEAEs. The most frequently reported TEAEs in the OCT group were dysgeusia $(n=32)$, tongue discoloration $(n=9)$, and headache $(n=4)$. In the placebo group, oral discomfort $(n=3)$, dysgeusia $(n=2)$, and headache $(n=2)$ occurred most often. The remaining events were reported by $<5 \%$ of individuals in any treatment group. Out of 83 TEAEs, 63 TEAEs were considered being treatment-related (possible, probably or definitely related), 56 of them were reported by OCT-group members and 7 by participants of the placebo group.

Table 3 Bacterial counts in saliva

\begin{tabular}{|c|c|c|c|c|c|c|}
\hline \multirow{2}{*}{$\begin{array}{l}\text { Bacterial } \\
\text { counts }\end{array}$} & \multicolumn{3}{|c|}{ OCT $(n=152)$} & \multicolumn{3}{|c|}{ Placebo $(n=49)$} \\
\hline & $\begin{array}{l}\text { Before 1st } \\
\text { rinse }\end{array}$ & $\begin{array}{l}\text { After 1st } \\
\text { rinse }\end{array}$ & $\begin{array}{l}\text { Count reduction } \\
\text { (lgRF) }\end{array}$ & $\begin{array}{l}\text { Before 1st } \\
\text { rinse }\end{array}$ & $\begin{array}{l}\text { After 1st } \\
\text { rinse }\end{array}$ & $\begin{array}{l}\text { Count reduction } \\
\text { (lgRF) }\end{array}$ \\
\hline Median & 6.550 & 3.815 & $2.725^{*}$ & 6.570 & 6.310 & 0.240 \\
\hline $\begin{array}{l}\text { Min-max } \\
(\operatorname{lgCFU} / \mathrm{ml})\end{array}$ & $5.17-8.44$ & $0.00-11.38$ & -3.99 to 7.63 & $4.96-7.68$ & $5.22-7.32$ & -0.84 to 1.09 \\
\hline
\end{tabular}

*Between OCT and placebo groups; van Elteren test, 2-sided, $p<0.0001$, intention to treat analysis set $O C T$ octenidine mouthrinse, $C F U$ colony forming units, $\max$ maximum, $\min$ minimum, $\lg R F \log$ reduction factor, $n$ number of subjects 


\section{Discussion}

The analysis of the study data clearly demonstrated the superiority of the $0.1 \%$ OCT mouthwash over placebo in the inhibition of plaque re-growth over a 5 -day period in the absence of mechanical plaque control. This evidence is in line with the observed marked reduction of salivary bacterial counts after a single rinse with the $0.1 \%$ OCT mouthwash. The validity of the plaque re-growth model by Addy and co-workers used in this trial for the evaluation of plaque re-growth inhibition $[1,24]$ is well established and has been successfully applied in many other clinical studies before [33-36].

The reduction of dental plaque formation over the period of 5 days was statistically significant and may be considered clinically relevant. In fact, subjects of the OCT group had a total median PI score of 0.36 after 5 days of OCT mouthwash use as the only personal oral hygiene measure compared to a median PI score of 1.29 in the placebo group. The median PI score in the OCT group at V2 roughly corresponded to the median PI score observed at V1 for the total of the study population (PI 0.33) supporting the conclusion that the regular use of the $0.1 \%$ OCT mouthwash has the same antibacterial efficacy as routine mechanical oral hygiene measures. Similar observations were made in other studies using mouthrinses containing $0.1 \%$ octenidine $[23,37-40]$ or other antiseptic agents (e.g., chlorhexidine) [33, 41, 42]. The distinct bacterial count reduction by the use of a $0.1 \%$ OCT mouthwash observed in this study confirms the data of the phase II trial [23].

In comparison to the golden standard CHX, bacterial reduction and plaque inhibition occurred to a similar extent [42-44]. So far, it can be speculated that OCT would have a similar effect on bacteria and plaque. However, a future clinical study with CHX as positive control should prove this hypothesis.

While the inclusion criteria allowed to include study subjects with mild to moderate chronic gingivitis up to a mean GI score of 1.5, the overall baseline mean GI score of the study population was GI 0.40 . Only 13 recruited study participants $(6 \%)$ had a mean GI score $>1.0$ and were suffering from moderate gingivitis. Nevertheless, the use of the OCT mouthwash resulted in a statistically significant inhibition of gingival inflammation, although the observed median reduction of $\mathrm{GI}=0.04$ may not be considered clinically relevant.

As reported in many other studies evaluating antiseptic mouthrinses before, tooth and tongue discoloration was the most frequently reported adverse event followed by dysgeusia $[23,37]$. The observed differences in DI between OCT and placebo were statistically significant but are considered clinically not relevant as they represent a median difference of 0.25 on a 0 to 3 grading scale only. As tea/coffee consumption, tobacco smoking and tobacco chewing are well known to have a significant impact on tooth discoloration [45], they were recorded during this study, but no effect was proven (ANCOVA, 2-sided, $p>0.05$ ).

\section{Strengths and limitations}

As the recording of PI and GI scores was restricted to the Ramfjord teeth, the true extent of plaque re-growth and accompanied gingival inflammation within the dentition might have been underestimated. However, this systematic bias would have affected both groups equally. The general validity of study data gained by the evaluation of the Ramfjord teeth has been verified in various other studies $[28,46,47]$. Correlations between the two approaches were high. Authors reported an underestimation of 0 scores and overestimation of $2+3$ scores [48]. The pooled analysis of the studies increased the sample size and leads to more reliable results with increased precision and power as compared to the individual studies. A center effect was revealed for the primary parameter. Reasons for this could not be elucidated. However, if it was due to different investigator judgment, this subjective judgment was the same in test and control groups and therefore should not have had a negative impact on the outcome. A 3:1 ratio of participants in favor to the OCT group was chosen to increase the number of OCT subjects for safety evaluation of the experimental agent. This approach could have led to some overestimation of the effects.

\section{Conclusion}

Repeated rinsing with a $0.1 \%$ octenidine mouthwash is an efficacious measure for the temporary inhibition of plaque re-growth and the maintenance of gingival health in the absence of personal mechanical plaque control during 5 days.

Supplementary Information The online version contains supplementary material available at https://doi.org/10.1007/s00784-021-03781-3.

Acknowledgments We want to thank Prof. Apostolos Georgopoulos for the bacterial assessments and Muazzez Arslan for the administrative study support at the Medical University of Vienna. Thanks to Leonie Fahl and Dr. Karolin Höfer for helping with the organization on site and to Prof. Dr. Hilmar Wisplinghoff and Dr. Angela Nowag for organizing and conducting the laboratory tests in Cologne. We want to thank Dr. Peggy Stölzel, Dr. Jeanine Hess, and Nicole Petersen for clinical data collection and the MEDLAB Arnold Analytik for the bacterial assessments. We are most grateful to Prof. Dr. Thomas Hoffmann for his visionary initiative in designing this study and his continuous support, to Nour Tassabehji, MSc. for clinical data collection and to Dr. Christian Lück, Kerstin Lück, and Susan Menzel for performing the laboratory tests at TU Dresden. We thank the laboratory "Dr. Reising-Ackermann" (Dr. Agneta Mewes) for performing the laboratory analyses in Leipzig. We want to thank Prof. Dr. Peter Eickholz for helping with the organization and conception on site, Mrs. Ivana Elez, BSc. who supported the study as 
study nurse, and Mrs. Jordan for organizing and conducting the laboratory tests in Frankfurt am Main.

Authors' contributions All authors contributed to the study conception and design. Material preparation, data collection, and analysis were performed by Yvonne Jockel-Schneider and Katrin Lorenz. The first draft of the manuscript was written by Yvonne Jockel-Schneider, and all authors commented on previous versions of the manuscript. All authors read and approved the final manuscript.

Funding Open Access funding enabled and organized by Projekt DEAL. The realization of this trial was funded by Schülke \& Mayr GmbH (Norderstedt, Germany).

\section{Compliance with ethical standards}

Conflict of interest The authors declare that they have no conflict of interest.

Ethical approval All procedures performed involving human participants were in accordance with the ethical standards of the ethics committees of the University of Dresden and the University of Wuerzburg and with the 1964 Helsinki declaration and its later amendments or comparable ethical standards.

Informed consent Informed consent was obtained from all individual participants included in the study.

Open Access This article is licensed under a Creative Commons Attribution 4.0 International License, which permits use, sharing, adaptation, distribution and reproduction in any medium or format, as long as you give appropriate credit to the original author(s) and the source, provide a link to the Creative Commons licence, and indicate if changes were made. The images or other third party material in this article are included in the article's Creative Commons licence, unless indicated otherwise in a credit line to the material. If material is not included in the article's Creative Commons licence and your intended use is not permitted by statutory regulation or exceeds the permitted use, you will need to obtain permission directly from the copyright holder. To view a copy of this licence, visit http://creativecommons.org/licenses/by/4.0/.

\section{References}

1. Addy M, Moran JM (1997) Clinical indications for the use of chemical adjuncts to plaque control: chlorhexidine formulations. Periodontol 15:52-54

2. Ozcaka O, Basoglu OK, Buduneli N, Tasbakan MS, Bacakoglu F, Kinane DF (2012) Chlorhexidine decreases the risk of ventilatorassociated pneumonia in intensive care unit patients: a randomized clinical trial. J Periodontal Res 47(5):584-592. https://doi.org/10. 1111/j.1600-0765.2012.01470.x

3. Arweiler NB, Auschill TM, Sculean A (2018) Patient self-care of periodontal pocket infections. Periodontol 76(1):164-179. https:// doi.org/10.1111/prd.12152

4. Chapple IL, Van der Weijden F, Doerfer C, Herrera D, Shapira L, Polak D, Madianos P, Louropoulou A, Machtei E, Donos N, Greenwell H, Van Winkelhoff AJ, Eren Kuru B, Arweiler N, Teughels W, Aimetti M, Molina A, Montero E, Graziani F (2015) Primary prevention of periodontitis: managing gingivitis. J Clin Periodontol 42(Suppl 16):S71-S76. https://doi.org/10.1111/jcpe. 12366
5. Bonesvoll P, Gjermo P (1978) A comparision between chlorhexidine and some quaternary ammonium compounds with regard to retention, salivary concentration and plaque-inhibiting effect in the human mouth after mouth rinses. Arch Oral Biol 23(4):289-294

6. da Silveira TD, de Figueiredo MAZ, Cherubini K, de Oliveira SD, Salum FG (2019) The topical effect of chlorhexidine and povidoneiodine in the repair of oral wounds. A review. Stomatologija 21(2): $35-41$

7. Sanchez IR, Swaim SF, Nusbaum KE, Hale AS, Henderson RA, McGuire JA (1988) Effects of chlorhexidine diacetate and povidone-iodine on wound healing in dogs. Vet Surg 17(6):291295. https://doi.org/10.1111/j.1532-950x.1988.tb01019.x

8. Slots J (2002) Selection of antimicrobial agents in periodontal therapy. J Periodontal Res 37(5):389-398

9. Van Strydonck DA, Slot DE, Van der Velden U, Van der Weijden F (2012) Effect of a chlorhexidine mouthrinse on plaque, gingival inflammation and staining in gingivitis patients: a systematic review. J Clin Periodontol 39(11):1042-1055. https://doi.org/10. 1111/j.1600-051X.2012.01883.x

10. James P, Worthington HV, Parnell C, Harding M, Lamont T, Cheung A, Whelton H, Riley P (2017) Chlorhexidine mouthrinse as an adjunctive treatment for gingival health. Cochrane Database Syst Rev 3:CD008676. https://doi.org/10.1002/14651858. CD008676.pub2

11. Bailey DM, DeGrazia CG, Hoff SJ, Schulenberg PL, O'Connor JR, Paris DA, Slee AM (1984) Bispyridinamines: a new class of topical antimicrobial agents as inhibitors of dental plaque. J Med Chem 27(11):1457-1464. https://doi.org/10.1021/jm00377a014

12. Koburger T, Hubner NO, Braun M, Siebert J, Kramer A (2010) Standardized comparison of antiseptic efficacy of triclosan, PVPiodine, octenidine dihydrochloride, polyhexanide and chlorhexidine digluconate. J Antimicrob Chemother 65(8):1712-1719. https://doi.org/10.1093/jac/dkq212

13. Hubner NO, Siebert J, Kramer A (2010) Octenidine dihydrochloride, a modern antiseptic for skin, mucous membranes and wounds. Skin Pharmacol Physiol 23(5):244-258. https://doi. org/10.1159/000314699

14. Schmidt J, Zyba V, Jung K, Rinke S, Haak R, Mausberg RF, Ziebolz D (2016) Cytotoxic effects of octenidine mouth rinse on human fibroblasts and epithelial cells - an in vitro study. Drug Chem Toxicol 39(3):322-330. https://doi.org/10.3109/01480545. 2015.1121274

15. Schmidt J, Zyba V, Jung K, Rinke S, Haak R, Mausberg RF, Ziebolz D (2018) Effects of octenidine mouth rinse on apoptosis and necrosis of human fibroblasts and epithelial cells - an in vitro study. Drug Chem Toxicol 41(2):182-187. https://doi.org/10.1080/ 01480545.2017 .1337124

16. Assadian O (2016) Octenidine dihydrochloride: chemical characteristics and antimicrobial properties. J Wound Care 25(3 Suppl): S3-S6. https://doi.org/10.12968/jowc.2016.25.Sup3.S3

17. Brill F, Goroncy-Bermes P, Sand W (2006) Influence of growth media on the sensitivity of Staphylococcus aureus and Pseudomonas aeruginosa to cationic biocides. Int J Hyg Environ Health 209(1):89-95. https://doi.org/10.1016/j.ijheh.2005.08.007

18. Ghannoum MA, Elteen KA, Ellabib M, Whittaker PA (1990) Antimycotic effects of octenidine and pirtenidine. J Antimicrob Chemother 25(2):237-245. https://doi.org/10.1093/jac/25.2.237

19. Ghannoum MA, Moussa NM, Whittaker P, Swairjo I, Abu-Elteen KH (1992) Subinhibitory concentration of octenidine and pirtenidine: influence on the lipid and sterol contents of Candida albicans. Chemotherapy 38(1):46-56. https://doi.org/10.1159/ 000238941

20. Pitten FA, Werner HP, Kramer A (2003) A standardized test to assess the impact of different organic challenges on the antimicrobial activity of antiseptics. J Hosp Infect 55(2):108-115 
21. Kramer A, Hoppe H, Krull B, Pitten FA, Rosenau S (1998) Antiseptic efficacy and acceptance of Octenisept computed with common antiseptic mouthwashes. Zentralbl Hyg Umweltmed 200(5-6):443-456

22. Pitten FA, Kramer A (1999) Antimicrobial efficacy of antiseptic mouthrinse solutions. Eur J Clin Pharmacol 55(2):95-100

23. Lorenz K, Jockel-Schneider Y, Petersen N, Stolzel P, Petzold M, Vogel U, Hoffmann T, Schlagenhauf U, Noack B (2018) Impact of different concentrations of an octenidine dihydrochloride mouthwash on salivary bacterial counts: a randomized, placebocontrolled cross-over trial. Clin Oral Investig 22(8):2917-2925. https://doi.org/10.1007/s00784-018-2379-0

24. Addy M, Willis L, Moran J (1983) Effect of toothpaste rinses compared with chlorhexidine on plaque formation during a 4-day period. J Clin Periodontol 10(1):89-99

25. Silness J, Loe H (1964) Periodontal disease in pregnancy. II. Correlation between oral hygiene and periodontal condition. Acta Odontol Scand 22:121-135

26. Loe $H$ (1967) The gingival index, the plaque index and the retention index systems. J Periodontol 38(6):Suppl:610-Suppl:616. https:// doi.org/10.1902/jop.1967.38.6.610

27. Ramfjord SP (1959) Indices for prevalence and incidence of periodontal disease. J Periodontol 30:51-59

28. Fleiss JL, Park MH, Chilton NW, Alman JE, Feldman RS, Chauncey HH (1987) Representativeness of the "Ramfjord teeth" for epidemiologic studies of gingivitis and periodontitis. Community Dent Oral Epidemiol 15(4):221-224. https://doi.org/ 10.1111/j.1600-0528.1987.tb00525.x

29. Khocht A, Zohn H, Deasy M, Chang KM (1995) Assessment of periodontal status with PSR and traditional clinical periodontal examination. J Am Dent Assoc 126(12):1658-1665. https://doi.org/ 10.14219/jada.archive.1995.0115

30. Brecx M, Macdonald LL, Legary K, Cheang M, Forgay MG (1993) Long-term effects of Meridol and chlorhexidine mouthrinses on plaque, gingivitis, staining, and bacterial vitality. J Dent Res 72(8):1194-1197

31. Hefti AF, Preshaw PM (2012) Examiner alignment and assessment in clinical periodontal research. Periodontol 59(1):41-60. https:// doi.org/10.1111/j.1600-0757.2011.00436.x

32. Schulz KF, Altman DG, Moher D, Group C (2010) CONSORT 2010 statement: updated guidelines for reporting parallel group randomised trials. PLoS Med 7(3):e1000251. https://doi.org/10. 1371/journal.pmed.1000251

33. Arweiler NB, Henning G, Reich E, Netuschil L (2002) Effect of an amine-fluoride-triclosan mouthrinse on plaque regrowth and biofilm vitality. J Clin Periodontol 29(4):358-363

34. Pizzo G, Guiglia R, La Cara M, Giuliana G, D'Angelo M (2004) The effects of an amine fluoride/stannous fluoride and an antimicrobial host protein mouthrinse on supragingival plaque regrowth. $\mathrm{J}$ Periodontol 75(6):852-857. https://doi.org/10.1902/jop.2004. 756852

35. Binney A, Addy M, McKeown S, Everatt L (1995) The effect of a commercially available triclosan-containing toothpaste compared to a sodium-fluoride-containing toothpaste and a chlorhexidine rinse on 4-day plaque regrowth. J Clin Periodontol 22(11):830 834. https://doi.org/10.1111/j.1600-051x.1995.tb01780.x
36. Singh A, Daing A, Dixit J (2013) The effect of herbal, essential oil and chlorhexidine mouthrinse on de novo plaque formation. Int $\mathrm{J}$ Dent Hyg 11(1):48-52. https://doi.org/10.1111/j.1601-5037.2012. 00556.x

37. Beiswanger BB, Mallatt ME, Mau MS, Jackson RD, Hennon DK (1990) The clinical effects of a mouthrinse containing $0.1 \%$ octenidine. J Dent Res 69(2):454-457. https://doi.org/10.1177/ 00220345900690020701

38. Patters MR, Anerud K, Trummel CL, Kornman KS, Nalbandian J, Robertson PB (1983) Inhibition of plaque formation in humans by octenidine mouthrinse. J Periodontal Res 18(2):212-219

39. Patters MR, Nalbandian J, Nichols FC, Niekrash CE, Kennedy JE, Kiel RA, Trummel CL (1986) Effects of octenidine mouthrinse on plaque formation and gingivitis in humans. J Periodontal Res 21(2): 154-162. https://doi.org/10.1111/j.1600-0765.1986.tb01447.x

40. Welk A, Zahedani M, Beyer C, Kramer A, Muller G (2016) Antibacterial and antiplaque efficacy of a commercially available octenidine-containing mouthrinse. Clin Oral Investig 20(7):1469 1476. https://doi.org/10.1007/s00784-015-1643-9

41. Moran J, Addy M, Wade W, Milson S, McAndrew R, Newcombe RG (1995) The effect of oxidising mouthrinses compared with chlorhexidine on salivary bacterial counts and plaque regrowth. J Clin Periodontol 22(10):750-755

42. Rosin M, Welk A, Kocher T, Majic-Todt A, Kramer A, Pitten FA (2002) The effect of a polyhexamethylene biguanide mouthrinse compared to an essential oil rinse and a chlorhexidine rinse on bacterial counts and 4-day plaque regrowth. J Clin Periodontol 29(5):392-399

43. Welk A, Zahedani M, Beyer C, Kramer A, Muller G (2015) Antibacterial and antiplaque efficacy of a commercially available octenidine-containing mouthrinse. Clin Oral Investig 20(7):14691476. https://doi.org/10.1007/s00784-015-1643-9

44. Arweiler NB, Boehnke N, Sculean A, Hellwig E, Auschill TM (2006) Differences in efficacy of two commercial $0.2 \%$ chlorhexidine mouthrinse solutions: a 4-day plaque re-growth study. J Clin Periodontol 33(5):334-339. https://doi.org/10.1111/j.1600-051X. 2006.00917.x

45. Watts A, Addy M (2001) Tooth discolouration and staining: a review of the literature. Br Dent J 190(6):309-316. https://doi.org/10. 1038/sj.bdj.4800959a

46. Mumghamba EG, Pitiphat W, Matee MI, Simon E, Merchant AT (2004) The usefulness of using Ramfjord teeth in predicting periodontal status of a Tanzanian adult population. J Clin Periodontol 31(1):16-18

47. Bentley CD, Disney JA (1995) A comparison of partial and full mouth scoring of plaque and gingivitis in oral hygiene studies. $\mathrm{J}$ Clin Periodontol 22(2):131-135

48. Silness J, Røynstrand T (1988) Partial mouth recording of plaque, gingivitis and probing depth in adolescents. J Clin Periodontol 15(3):189-192. https://doi.org/10.1111/j.1600-051x.1988. tb01568.x

Publisher's note Springer Nature remains neutral with regard to jurisdictional claims in published maps and institutional affiliations. 